$\xi=-1$

\title{
Student nurses' knowledge of guidelines for preventing central venous catheter-associated infections
}

\author{
Mohammad Al Qadire, RN, MSN, Phd ${ }^{1 *}$, Loai Tawalbeh, RN, MSN, Phd ${ }^{2}$, Mohammad Suliman, RN, MSN, Phd ${ }^{3}$ \\ ${ }^{1}$ Head of Adult Healthcare Nursing Department Dean Assistant for Students Affairs Faculty of Nursing Al Al-Bayt University \\ ${ }^{2}$ Associate Professor Adult Healthcare Nursing Department Faculty of Nursing Al Al-Bayt University \\ ${ }^{3}$ Assistant Professor Community and Mental Health Department Faculty of Nursing Al Al-Bayt University \\ *Corresponding author E-mail: mohammadqadire@aabu.edu.jo
}

\begin{abstract}
Background: Despite the advantages of Central venous catheters (CVC), patients are at high risk of infection (local and systematic) that could be lethal. Lack of knowledge of the available guidelines for the prevention of CVC-associated infection may increase the rate of CVC-associated infections.

Objective: The purpose of the study is to evaluate student nurses' knowledge of the guidelines for preventing CVC-associated infection. Methods: A descriptive cross-sectional survey was used. This study involved 267 student nurses from four government universities. They were in their second-, third- or fourth-year of study.

Results: Most of the students were female (72.3\%) with a mean age of 21.2 (SD 2.5). The mean total score of students' knowledge was very low at 1.6 (SD 1.5) out of 10, the maximum score, and ranged from 0 to 7 . Students who reported having received adequate theoretical and clinical education about CVC had higher mean total knowledge scores than those who had not.

Conclusions: The results showed that Jordanian student nurses have insufficient knowledge about the prevention of CVC-associated infection. In order to improve their knowledge, an evidence-based teaching approach is required in the theoretical classes. This should be combined with the best clinical training through the use of simulation techniques.
\end{abstract}

Keywords: Central Venous Catheters; Jordan; Nursing; Students`Knowledge.

\section{Introduction}

Central venous catheters (CVC) are widely used in intensive care units, renal dialysis units, and oncology departments (Kelly et al., 2015; Mlinar and Rašković-Malnaršić, 2012; Ullman et al., 2014). They are usually used for blood sampling, and for administration of medication, chemotherapy, blood products, intravenous fluids and parental nutrition (Chopra et al., 2013; Mlinar and RaškovićMalnaršić, 2012). They allow for giving large amounts of fluid in a shorter time than the classical peripheral access (cannulas) (Chopra et al., 2013; Mlinar and Rašković-Malnaršić, 2012; Ullman et al., 2014). Despite the advantages of CVCs, patients are at high risk of infection (local and systematic) that could be lethal (Mlinar and Rašković-Malnaršić, 2012; Tomlinson et al., 2011). Such infections result in a high mortality rate, a longer hospitalization period, and increase the cost of healthcare (Frasca et al., 2010; Mlinar and Rašković-Malnaršić, 2012; Tomlinson et al., 2011). Many factors can increase the risk of CVC-associated infections, including poor health status, immuno-compromised patients, the location of the insert site, the type of CVC, and long hospitalization (Alkubati et al., 2015; Frasca et al., 2010; Scales, 2011; Tomlinson et al., 2011). However, another important cause of CVC-associated infection is that healthcare providers in general and nurses in particular lack the required knowledge and skills to provide optimal care for CVC patients (Gra and Cruz, 2015; Kelly et al., 2015; Snarski et al., 2015). Lack of knowledge may result in low adherence to the available guidelines for the prevention of CVC-associated infection. Nurses always have the main responsi- bility for CVC care, such as assisting in the insertion procedure, dressing, flushing, blood sampling, and adminsitrion of fluid, medication, chemotherapy and other liquids that can be given through CVCs (Gra and Cruz, 2015; Ullman et al., 2014). They also responsible for teaching the patients and family caregivers how to care for catheters at home. Hence, they form the first line in the reduction of CVC-associated complications, and infection in particular. Unfortunately, previous studies confirm that nurses have insufficient knowledge regarding the guidelines for preventing CVC-associated infection (Gra and Cruz, 2015; Kelly et al., 2015; Snarski et al., 2015). One possible reason is the inadequate education and training of nurses during their undergraduate studies (Mlinar and Rašković-Malnaršić, 2012). Only one study has been found that investigated student nurses' knowledge of CVC care (Mlinar and Rašković-Malnaršić, 2012). The authors used a questionnaire that was specifically designed for the purpose of the study. They included 87 full-time students and 57 part-time students in their second year. The results show that student nurses had insufficient knowledge about all aspects of CVC care. They had poor knowledge of the indicators of a fully functioning catheter, signs and symptoms of infection and the recommended frequency of catheter flushing and replacement. Thus, the purpose of the study is to evaluate student nurses' knowledge of the guidelines for preventing CVC-associated infection. 


\section{Method}

\subsection{Design}

A cross-sectional survey design was used.

\subsection{Sample and settings}

This study involved 267 student nurses from four government universities, all located in the central and north of Jordan. Second, third- and fourth-year students were asked to take part in the study. Ethical approval from the appropriate authorities was sought. All students were invited personally to participate in the study. 500 questionnaires were distributed; 267 were returned completed and were eligible for analysis (response rate of 53.4\%).

\subsection{Data collection}

The study questionnaire was completed in face-to-face interviews Research assistants visited the selected universities on one occasion and distributed the questionnaires to students. A briefing about the study objective and procedure was given to participants in their classrooms. We then asked the students who agreed to participate to complete the questionnaire and put it in a box in the room. It took them 10 to 15 minutes to complete the questionnaire.

\subsection{Questionnaire}

The questionnaire content was developed by the authors based on the 2011 guidelines for the prevention of intravascular catheterrelated infections (Centers for Disease and Prevention, 2011) and previous literature (Alkubati et al., 2015; Chen et al., 2015; Koutzavekiaris et al., 2011; Snarski et al., 2015). It comprised ten multiple-choice questions with only one possible correct answer and two distractor answers. However, an "I do not know" option was included to evade guessing. The questionnaire content was reviewed and revised for its relevance and appropriateness by three clinicians (head of infection control, two head nurses of oncology units) and two PhD holders. It had been used in another study conducted by the author on oncology nurses; the Cronbach alpha for the questionnaire was satisfactory at 0.78 . Each correct answer was given one point and other choices, if selected, given zero, so the total score could range from zero to ten. General information about students, such as age, gender, year of study and previous education and clinical training on CVC care, was collected.

\section{Data analysis}

Data was analysed using the Statistical Package for Social Science (SPSS version 21). Descriptive statistics such as mean, standard deviation, frequency and percentage were computed to describe the sample and their response on the knowledge questionnaire. The mean total knowledge score was compared against students' characteristics using the independent t-test.

\section{Results}

\subsection{Participants' demographics}

A total of 267 student nurses from four government universities in the middle and north of Jordan completed the study questionnaire. Most of the students were female $(72.3 \%)$ with a mean age of 21.2 (SD 2.5) year (see Table 1).
Table 1: Demographic Characteristics of Nursing Students $(\mathrm{N}=267)$

\begin{tabular}{ll}
\hline Characteristic & Frequency (\%) \\
\hline Gender & $74(27.7)$ \\
Male & $193(72.3)$ \\
Female & $75(28.2)$ \\
Study year & $109(40.8)$ \\
Second year & $83(31.0)$ \\
Third year & \\
Fourth year & $250(93.6)$ \\
Type of Admission & $17(6.4)$ \\
Regular admission & \\
Bridging system & $133(49.8)$ \\
Previous education about CVC care & $134(50.2)$ \\
Yes & \\
No & \\
Have you received adequate clinical training on CVC \\
care?
\end{tabular}

\subsection{Students' knowledge of CVC care}

The mean total score of students' knowledge was very low at 1.6 (SD 1.5) out of 10, the maximum score, and ranged from 0 to 7. The best answered question was question one; $24.3 \%$ of students knew the correct answer (see Table 2). All other questions were answered correctly by less than $19.1 \%$ of the students. Only $8.2 \%$ of students knew that $2 \%$ chlorhexidine is the recommended disinfectant solution to clean the insertion site of the CVC (question 5). A similar percentage of students was only able to recognize that it is recommended to replace the administration set every 96 hours when lipid emulsion or blood products are not given (question 8). Nevertheless, $89 \%$ of students erroneously thought that application of antibiotic ointments on the insertion site is recommended (question 6). Although hand washing is recommended as standard in daily practice, only $13.9 \%$ of students knew that hand washing is recommended with the main steps while caring for CVC patients (question 9). Complete details of students' correct answers are detailed in Table 2 .

\subsection{Two-group comparisons}

To further understand if there is a difference in the mean total knowledge score of students with regard to their characteristics, independent t-tests were conducted. There was no significant difference in the mean total score in regard to students' gender or type of admission $(p>.05)$. However, the results showed significant differences in the mean of total knowledge score in regard to receiving previous education about $\mathrm{CVC}$, receiving adequate clinical training in $\mathrm{CVC}$ care, and feeling confident when dealing with CVC in clinical.

Practice (see Table 3). All p values were $<.05$ and the $95 \%$ CI of the difference did not contain zero, which is consistent with the ttest results. Students who reported having received adequate theoretical and clinical education about CVC had higher mean total knowledge scores than those who had not. In addition, students who felt confident in dealing with CVC had significantly higher mean knowledge scores than those who did not feel confident. Finally, the one-way ANOVA test showed no significant difference in the mean knowledge score and students' year of study ( $p>$ $.05)$. 
Table 2: Correctly Answered Items on the CVC Care Knowledge Test ( $\mathrm{N}=267)$

\begin{tabular}{|c|c|c|c|}
\hline \multirow[t]{2}{*}{$\begin{array}{l}\text { Item } \\
\text { No. }\end{array}$} & \multirow[t]{2}{*}{ Question } & \multicolumn{2}{|c|}{$\begin{array}{l}\text { Correct Re- } \\
\text { sponses }\end{array}$} \\
\hline & & $\mathrm{n}$ & $\%$ \\
\hline 1 & It is recommended to replace central venous catheters (CVCs) routinely. (No, only when indicated) & 65 & 24.3 \\
\hline 3 & $\begin{array}{l}\text { It is recommended to change the dressing on the catheter insertion site? (When indicated (soiled, loosened, ...) and at least } \\
\text { weekly) }\end{array}$ & 45 & 16.9 \\
\hline 4 & $\begin{array}{l}\text { It is recommended to cover up the catheter insertion site with (Both are recommended because the type of dressing does not } \\
\text { affect the risk for catheter-related infections) }\end{array}$ & 45 & 16.9 \\
\hline 5 & It is recommended to disinfect the catheter insertion site with? ( $2 \%$ aqueous chlorhexidine) & 22 & 8.2 \\
\hline 6 & It is recommended to apply an antibiotic ointment at the insertion site of a CVC. (No, because it causes antibiotic resistance) & 30 & 11 \\
\hline 7 & When lipid emulsions are administered through a CVC it is recommended to replace the administration set? (Within 24 hours) & 57 & 21.3 \\
\hline 8 & $\begin{array}{l}\text { When neither lipid emulsions nor blood products are administered through a CVC it is recommended to replace the admin- } \\
\text { istration set. } \\
\text { (Every } 96 \text { hours) }\end{array}$ & 22 & 8.2 \\
\hline 9 & $\begin{array}{l}\text { According to the CDC guidelines, which one of the following statements about CVC ongoing care is incorrect: (Hands should } \\
\text { be only washed before opening the dressing pack and after removing the old dressing). }\end{array}$ & 37 & 13.9 \\
\hline
\end{tabular}

Table 3: Independent T-Test Results Analysing the Difference in Mean Total Knowledge Score between Two Groups

\begin{tabular}{|c|c|c|c|c|c|}
\hline Variable & $\mathrm{t}$ & df & $\mathrm{p}$ & $95 \% \mathrm{CI}$ of the difference & Mean (SD) \\
\hline $\begin{array}{l}\text { Gender } \\
\text { Male } \\
\text { Female }\end{array}$ & -1.82 & 265 & .070 & -0.80 to 0.32 & $\begin{array}{l}1.51(1.5) \\
1.89(1.7)\end{array}$ \\
\hline $\begin{array}{l}\text { Previous education a } \\
\text { Yes } \\
\text { No }\end{array}$ & -8.10 & 265 & .000 & -1.72 to -1.04 & $\begin{array}{l}2.31(1.6) \\
0.93(1.21)\end{array}$ \\
\hline $\begin{array}{l}\text { Feeling confident wl } \\
\text { Yes } \\
\text { No }\end{array}$ & -4.50 & 265 & .000 & -1.37 to -0.54 & $\begin{array}{l}2.3(1.7) \\
1.38(1.4)\end{array}$ \\
\hline $\begin{array}{l}\text { Type of Admission } \\
\text { Regular admission } \\
\text { Bridging system }\end{array}$ & 0.88 & 265 & .381 & -0.42 to 1.11 & $\begin{array}{l}1.64(1.6) \\
1.29(1.2)\end{array}$ \\
\hline
\end{tabular}

\section{Discussion}

This study demonstrated that Jordanian student nurses have a very low knowledge level of the various guidelines to prevent CVCassociated infection. Because no similar studies have been conducted on the same topic, comparing our results to other research is limited. As indicated above, only one study was found on student nurses, although it did explore students' overall knowledge of CVC (Mlinar and Rašković-Malnaršić, 2012). With regard to preventing CVC infections, our students seem to have even lower levels of knowledge. They knew almost nothing about how to prevent $\mathrm{CVC}$-associated infection, which represents a possibility of risky practice that negatively affects patients' safety. Their lack of knowledge may also increase the rate of healthcare-related bloodstream infections (HBSI). A study conducted in Jordan reported that the HBSI rate was 8.1 per 1000 admissions (AlRawajfah et al., 2013). HBSI was found to increase the duration of hospitalization for infected patients by 12.7 days over noninfected patients, and to increase the total healthcare cost (AlRawajfah et al., 2013). The current level of knowledge of student nurses needs to be further investigated; hence we recommend replication studies at local and international levels. This would allow better evaluation of the current status and validate the results of the current study. Until that time, nursing scholars (particularly in Jordan) are strongly encouraged to incorporate the guidelines for prevention of intravascular catheter-related infections (Centers for Disease and Prevention, 2011) within their undergraduate courses to compensate for this need. In addition, course syllabus reform is needed. Previous studies have shown that short courses on CVC care improved nurses' knowledge and adherence to the current guidelines for prevention of related infection (Deshmukh and Shinde, 2014; Kelly et al., 2015; Zingg et al., 2014).

In this study, a tool to evaluate knowledge of the guidelines for preventing CVC-associated infection was developed by the authors. This tool needs to be further validated within different contexts to improve its internal validity; although it has been subjected to content validation, further content and psychometric testing is required. This would allow researchers to measure knowledge precisely. Furthermore, using a unified validated tool would allow comparison of the results of studies conducted within different contexts, and help in testing the effectiveness of education intervention in improving student nurses' knowledge. As a final note to prospective researchers, correlating the education intervention with selected patients' outcomes, for example the rate of CVC infection before and after the intervention, would be a crucial addition to their study. The results of this study should be understood in the light of the following shortcomings. First, this study recruited the sample conveniently and only from four government universities, which may limit the generalizability of the results to the participating universities. Prospective researchers are strongly recommended to select the participants randomly and to include students from all the nursing schools in the country. Second, the evaluation tool used is thought to objective, but this is its first use and it has not been previously validated, which may represent both internal and external validity threats. Despite these limitations, this study is the first of its kind, and it highlights an important gap in nursing education that needs to be quickly addressed. It also will also encourage nursing scholars in other parts of the world to assess their students' knowledge about this crucial topic 


\section{Conclusions}

The results show that Jordanian student nurses have insufficient knowledge about the prevention of CVC-associated infection. In order to improve their knowledge, an evidence-based teaching approach is required in the theoretical classes. This should be combined with the best clinical training though the use of simulation techniques. Such changes will naturally result from reform of course syllabuses, and research to test the feasibility and effectiveness of these changes in improving undergraduate nurses' knowledge.

\section{References}

[1] Al-Rawajfah, O.M., Cheema, J., Hewitt, J.B., Hweidi, I.M., Musallam, E., 2013. Laboratory-confirmed, health care-associated bloodstream infections in Jordan: A matched cost and length of stay study. American journal of infection control 41, 607-611. https://doi.org/10.1016/j.ajic.2012.08.014.

[2] Alkubati, S.A., Ahmed, N.T., Mohamed, O.N.E., Fayed, A.M Asfour, H.I., 2015. Health care workers' knowledge and practices regarding the prevention of central venous catheter-related infection. American journal of infection control 43, 26-30. https://doi.org/10.1016/j.ajic.2014.09.021.

[3] Centers for Disease, C., Prevention, 2011. Guidelines for the prevention of intravascular catheter-related infections, 2011. Washington: CDC.

[4] Chen, S., Yao, J., Chen, J., Liu, L., Miu, A., Jiang, Y., Zhu, J., Tang, S., Chen, Y., 2015. Knowledge of Guidelines for the prevention of intravascular catheter-related infections (2011): A survey of intensive care unit nursing staffs in China. International Journal of Nursing Sciences 2, 383-388. https://doi.org/10.1016/j.ijnss.2015.10.002.

[5] Chopra, V., O'Horo, J.C., Rogers, M.A.M., Maki, D.G., Safdar, N., 2013. The risk of bloodstream infection associated with peripherally inserted central catheters compared with central venous catheters in adults: a systematic review and meta-analysis. Infection Control \& Hospital Epidemiology 34, 908-918. https://doi.org/10.1086/671737.

[6] Deshmukh, M., Shinde, M., 2014. Impact of structured education on knowledge and practice regarding venous access device care among nurses. International Journal of Science and Research (IJSR) 3, 895-901.

[7] Frasca, D., Dahyot-Fizelier, C., Mimoz, O., 2010. Prevention of central venous catheter-related infection in the intensive care unit. Critical Care 14, 1. https://doi.org/10.1186/cc8853.

[8] Gra, R.d.F.E.d.G., Cruz, I., 2015. Nurses performance on preventing the risk of infection caused by the use of central venous catheter in the highly complex customer-Dressing a systematic review of the literature. Journal of Specialized Nursing Care 7.

[9] Kelly, L.J., Green, A., Hainey, K., 2015. Implementing a new teaching and learning strategy for CVAD care. British Journal of Nursing 24. https://doi.org/10.12968/bjon.2015.24.sup8.s4.

[10] Koutzavekiaris, I., Vouloumanou, E.K., Gourni, M., Rafailidis, P.I., Michalopoulos, A., Falagas, M.E., 2011. Knowledge and practices regarding prevention of infections associated with central venous catheters: a survey of intensive care unit medical and nursing staff. American journal of infection control 39, 542-547. https://doi.org/10.1016/j.ajic.2010.11.003.

[11] Mlinar, S., Rašković-Malnaršić, R., 2012. Knowledge of nursing students about central venous catheters. Vojnosanitetski pregled 69 , 333-339.

[12] Scales, K., 2011. Reducing infection associated with central venous access devices. Nursing standard 25, 49-56. https://doi.org/10.7748/ns.25.36.49.s51.

[13] Snarski, E., Mank, A., Iacobelli, S., Hoek, J., StyczyÅ,,ski, J., Babic, A., Cesaro, S., Johansson, E., 2015. Current practices used for the prevention of central venous catheter associated infection in hematopoietic stem cell transplantation recipients: a survey from the Infectious Diseases Working Party and Nurses' Group of EBMT. Transplant Infectious Disease 17, 558-565. https://doi.org/10.1111/tid.12399.

[14] Tomlinson, D., Mermel, L.A., Ethier, M.-C., Matlow, A., Gillmeister, B., Sung, L., 2011. Defining bloodstream infections related to central venous catheters in patients with cancer: a systematic review. Clinical infectious diseases 53, 697-710. https://doi.org/10.1093/cid/cir523.
[15] Ullman, A.J., Long, D.A., Rickard, C.M., 2014. Prevention of central venous catheter infections: A survey of paediatric ICU nurses' knowledge and practice. Nurse education today 34, 202-207. https://doi.org/10.1016/j.nedt.2013.09.002.

[16] Zingg, W., Cartier, V., Inan, C., Touveneau, S., Theriault, M., Gayet-Ageron, A., Clergue, F., Pittet, D., Walder, B., 2014. Hospitalwide multidisciplinary, multimodal intervention programme to reduce central venous catheter-associated bloodstream infection. PloS one 9, e93898. https://doi.org/10.1371/journal.pone.0093898. 